\title{
Attitudes of Mothers of Preschool Children towards Vaccination
}

\author{
Gorjana Naletilići ${ }^{*}$, Iva Lukačević Lovrenčić ${ }^{2}$, Vajdana Tomićs ${ }^{3,4}$, Aida Mujkić \\ ${ }^{1}$ No current affiliation, ${ }^{2}$ University of Zagreb, School of Medicine, Andrija Štampar School of Public Health, ${ }^{3}$ University of \\ Mostar, School of Medicine, ${ }^{4}$ Mostar University Clinical Hospital, Clinic for Gynecology and Obstetrics
}

Correspondence: iva.luklovrencic@gmail.com; Tel.: + 38514590 185; Fax.: + 38514684441

Received: December 9, 2020, Accepted: June 8, 2021

\begin{abstract}
Objective. The aim of this paper is to explore mothers' attitudes towards vaccination. Methods. The study involved 200 mothers with at least one child up to the age of 7 years, who were admitted to the Maternity Ward or were seen for regular check-ups at the Clinic for Gynecology and Obstetrics at Mostar University Clinical Hospital from April 12, 2016 to July 27, 2016. For examining attitudes towards vaccination, the Dan Kahan questionnaire was culturally adapted. Results. The average attitude score was 3.24 ( $\mathrm{SD}=0.49$ ), which indicates a mostly neutral attitude, with a tendency towards a more positive attitude. We obtained a high percentage of the answer: "neither agree nor disagree" for almost all questions, which may either be a "hidden do not know", or it can mean a neutral opinion. The highest percentage of the answer "neither agree nor disagree" was for the connection between vaccination and autism. The results of the study did not find any association between the mothers' age, the number of children, their employment status or education level with the positivity of attitudes toward vaccination. Conclusion. Despite the fact that a large number of mothers surveyed have generally positive attitudes towards vaccination, since a large number responded with "neither agree nor disagree", organized intervention is needed between health professionals, parents, the children themselves, public health officials, governments, the technology sector, and civil society in order to encourage the development of positive attitudes towards vaccination.
\end{abstract}

Key Words: Vaccination - Child • Preschool • Mothers • Attitude.

\section{Introduction}

Vaccination has achieved much since the original work of Jenner 200 years ago. Over the past two centuries, there has been a significant increase in the number of vaccines available for the prevention of contagious diseases, primarily those that have the highest incidence in the pediatric population (1). The number of vaccines in use is higher than ever before, and work is underway to discover new vaccines (2). The number of polyvalent vaccines developed is increasing. The World Health Organization states that vaccination prevents two to three million deaths per year, but another 1.5 million deaths

${ }^{*}$ Master of Pharmacy. could be prevented if the global vaccination coverage was improved (3). For example, the percentage of infants completely vaccinated against diphtheria - tetanus - pertussis with DTP3 vaccine was maintained at a stable level of $83 \%$ from 2010 to 2013 (4). However, in recent years, even in highly developed countries with previously high vaccination coverage, especially in children, the observed fall in public trust in the vaccination process is resulting in an increase in the number of parents deciding not to vaccinate their children. In developing countries, socioeconomic conditions affect vaccination coverage, there is a lack of vaccines due to poverty, or health care systems are insufficiently developed. In contrast, the main obstacle to optimal vaccination coverage in countries with developed health 
care systems is the parents' refusal to vaccinate their children. Burns and Zimmerman state that the barriers that prevent vaccination can be divided into three categories: lack of knowledge about vaccination, fear of vaccine safety, and logistical problems that restrict access to vaccination services (for example complex vaccination schedules, unsuitable appointment times, long waiting times to receive vaccines, transport problems, cost problems) (5).

Since we live in a rapidly changing world, various factors encourage the public to re-examine the process of vaccination (6-9). As Jankovic points out, the undisputed success of vaccination over decades of use has been followed by the re-strengthening of antivaccination movements in recent years (10). Consequently, the vaccination coverage rate is decreasing, including the world's most economically developed countries with a high level of health education. Moreover, a significant number of medical doctors and other healthcare professionals are encouraging or actively propagating negative attitudes towards vaccination, which is particularly devastating considering the fact that, even in the modern era of the Internet, health care professionals are still the most important source of information about vaccination for most parents. Research looking at pertussis incidence in many developed countries has shown that, in countries where vaccine uptake for pertussis vaccination programs had decreased because of controversies, the incidence of pertussis was much higher than in countries where high vaccine coverage was maintained (11). There have been several studies examining the attitudes of parents to vaccination and its consequences, which showed the complexity and multidimensionality of factors shaping the parents' attitude towards vaccination $(12,13,14,15)$.

Parents' mistrust in vaccination and its possible adverse effects may also be the result of reports available on the Internet, as well as other media, insinuating that doctors receive financial benefits from the pharmaceutical industry. Many factors influence parents' decision to vaccinate their children, including their sociodemographic characteristics, their trust in the public health system, the parent-physician relationship, their level of knowledge, and their attitudes towards vaccination.
The objective of this research was to explore mothers' attitudes towards vaccination, and the possible effects of the mothers' age, education and employment status on attitudes to vaccination.

\section{Methods}

The research was conducted on a convenience sample of mothers with at least one child up to the age of 7 years, who were admitted to the Maternity Ward or came for regular check-ups to the Clinic for Gynecology and Obstetrics at Mostar University Clinical Hospital from April 2016 to July 2016.

\section{Participants}

Participation in the research was voluntary, anonymous, and all respondents signed informed consent. After a brief introduction about the research, the respondents were given an anonymous questionnaire by a nurse. The respondents filled in the questionnaire, placed it in an envelope, sealed it and returned it to the nurse who gave them the questionnaire. The questionnaire, designed by Professor Dan Kahan from Yale Law School, Harvard University - Edmond J. Safra Center for Ethics, was culturally adapted (16). The customized questionnaire consisted of two parts. In the first part, socioeconomic data on age, education, employment status, marital status and economic status of respondents were collected. The second part of the questionnaire contained 17 questions with Likert type responses from 1 (completely agree) to 5 (completely disagree) to claims referring to vaccination, such as trust in medicine, personal experiences, experiences of others, conspiracy theories, fear of financial exploitation, etc. Before the questionnaire was adapted and used, the consent of the author, Prof. Dan Kahan, was given via email on September 19, 2014.

\section{Statistical Analysis}

A database was created in the SPSS program for statistical analyses (version 21), and all analyses were performed using SPSS. Categorical variables 
are described with frequencies and percentages, continuous variables with means and standard deviations. Spearman's rho correlation coefficient was used to calculate associations among variables. Mann-Whitney U test was used to test differences between two independent groups. The test statistics were considered statistically significant if $\mathrm{P}$ $<0.05$.

\section{Results}

A total of 200 women participated in this study. The mean age of the respondents was 32.6 years, with the youngest being 20 years old, and the oldest 62 years old (Table 1 ).

\section{Table 1. Descriptive Statistics for the Participants' Age}

\begin{tabular}{llllll}
\hline \multirow{2}{*}{ Age } & $\mathrm{N}$ & Mean \pm SD & Median & Minimum & Maximum \\
\cline { 2 - 6 } & 200 & $32.6 \pm 7.33$ & 31 & 20 & 62 \\
\hline
\end{tabular}

Approximately $50 \%$ of the respondents had secondary school education, and $46 \%$ had a college or university education. The majority were married. The women were asked to self-assess their economic status. Approximately $93 \%$ of the respondents estimated their economic status as average, and a similar percentage self-assessed their economic status as below average and above average. Two respondents did not enter data on economic status. About half of the respondents were employed (Table 2).

Approximately half of the participants had one child, 33\% had two children, and approximately $16 \%$ had three or more children. The total number of children in the sample of 200 participants was 286. Distribution of the number of children per participant is presented in Table 3.

More than half of the mothers had a positive personal experience with vaccination, and about $10 \%$ declared that they disagreed. About $28 \%$ indicated that people they know had had a negative experience with vaccination. A very high percentage, $38.5 \%$, considered that the childhood vaccines are not tested enough for safety. On the other hand, $43 \%$ of mothers recognized that the vaccines given to children are for serious diseases. Also, $49 \%$ think

\section{Table 2. Socio-Demographic Characteristics of the} Participants

\begin{tabular}{|c|c|c|}
\hline \multicolumn{2}{|l|}{ Characteristics } & \multirow{2}{*}{$\begin{array}{l}\mathrm{N}(\%) \\
7(3.5) \\
\end{array}$} \\
\hline Education years & $\leq 8$ years (primary school) & \\
\hline & $9-12$ years (secondary school) & $101(50.5)$ \\
\hline & $\geq 14+$ years & $9(46.0)$ \\
\hline & Total & $200(100.0)$ \\
\hline \multirow[t]{5}{*}{ Marital status } & Single & $3(1.5)$ \\
\hline & Married & $189(95.0$ \\
\hline & Divorced & $6(3.0)$ \\
\hline & Extramarital union & $1(0.5)$ \\
\hline & Total & $199(100.0)$ \\
\hline \multirow[t]{4}{*}{ Economic status } & Above average & $7(3.5)$ \\
\hline & Average & $185(93.4)$ \\
\hline & Below average & $6(3.0)$ \\
\hline & Total & $198(100.0)$ \\
\hline \multirow[t]{3}{*}{ Working status } & Unemployed & $90(45.5)$ \\
\hline & Employed & $108(54.5)$ \\
\hline & Total & $198(100.0)$ \\
\hline
\end{tabular}

Table 3. Distribution of the Number of Children per Participant

\begin{tabular}{ll}
\hline Number of children & $\mathrm{N}(\%)$ \\
\hline 1 & $83(50.9)$ \\
\hline 2 & $54(33.1)$ \\
\hline 3 & $15(9.2)$ \\
\hline 4 & $8(4.9)$ \\
\hline 6 & $3(1.8)$ \\
\hline Total & $286(100.0)$ \\
\hline
\end{tabular}

that a decline in vaccination puts children at risk. In the opinion of $38 \%$ of mothers, those parents who decline to have their children receive recommended vaccinations put many other people at serious risk. About $49 \%$ were confident in the judgment of the public health officials who are responsible for identifying the generally recommended childhood vaccinations, and only $14 \%$ disagreed. The highest percentage of mothers, about $62 \%$, agreed that the state should ensure that every child receives all vaccines on the vaccination calendar. While about $44 \%$ agreed that vaccinations provide major benefits to children, $47 \%$ answered: "Neither agree nor 
disagree". An even higher percentage of the answer "Neither agree nor disagree", 58\%, related to the statement that the health benefits outweigh the health risks. One third of mothers did not agree that recommended vaccines pose a high risk to the children being vaccinated. A similar percentage did not agree that vaccines pose a higher risk of developing autism, $36 \%$, with a higher percentages for diabetes mellitus, $43 \%$, and cancer, $48 \%$. In general, mothers consider vaccination to be a safe and effective way to prevent diseases, and that there is an increase in Bosnia and Herzegovina (BA) in the number of parents who vaccinate their children in accordance with the vaccination calendar. For all the questions, a large proportion of respondents chose a neutral answer (neither agree nor disagree). The percentage of that answer for the question about the connection between vaccination and autism was the highest, 55\%. Lastly, 61.3\% agreed

Table 4. Distribution of Answers on Vaccination Attitudes Items

\begin{tabular}{|c|c|c|c|c|c|c|}
\hline \multirow{3}{*}{ Items } & \multicolumn{6}{|l|}{ Answers } \\
\hline & $\begin{array}{l}\text { Completely } \\
\text { disagree }\end{array}$ & Disagree & $\begin{array}{l}\text { Neither agree } \\
\text { nor disagree }\end{array}$ & Agree & $\begin{array}{l}\text { Completely } \\
\text { agree }\end{array}$ & Total \\
\hline & $\mathrm{N}(\%)$ & $\mathrm{N}(\%)$ & $\mathrm{N}(\%)$ & $\mathrm{N}(\%)$ & $\mathrm{N}(\%)$ & $\mathrm{N}(\%)$ \\
\hline I have a positive experience with vaccination. & $16(8.7)$ & $4(2.2)$ & $63(34.4)$ & $80(43.7)$ & $20(10.9)$ & $183(100.0)$ \\
\hline $\begin{array}{l}\text { Many people I know have a negative experience with } \\
\text { vaccination. }\end{array}$ & $9(4.9)$ & $71(38.4)$ & $53(28.6)$ & $41(22.2)$ & $11(5.9)$ & $185(100.0)$ \\
\hline Childhood vaccines are not tested enough for safety. & $11(6.0)$ & $33(18.1)$ & $68(37.4)$ & $50(27.5)$ & $20(11.0)$ & $182(100.0)$ \\
\hline $\begin{array}{l}\text { Vaccines are given to children to prevent diseases that } \\
\text { are not serious. }\end{array}$ & $15(8.2)$ & $64(34.8)$ & $65(35.3)$ & $34(18.5)$ & $6(3.3)$ & $184(100.0)$ \\
\hline $\begin{array}{l}\text { Parents who decline to have their children receive } \\
\text { recommended childhood vaccinations put their } \\
\text { children at serious risk. }\end{array}$ & $16(8.7)$ & $26(14.1)$ & $52(28.3)$ & $78(42.4)$ & $12(6.5)$ & $184(100.0)$ \\
\hline $\begin{array}{l}\text { Parents who decline to have their children receive } \\
\text { recommended childhood vaccinations put lots of other } \\
\text { people at serious risk. }\end{array}$ & $12(6.5)$ & $38(20.7)$ & $63(34.2)$ & $62(33.7)$ & $9(4.9)$ & $184(100.0)$ \\
\hline $\begin{array}{l}\text { I am confident in the judgment of the public health } \\
\text { officials who are responsible for identifying generally } \\
\text { recommended childhood vaccinations. }\end{array}$ & $6(3.3)$ & $19(10.4)$ & $67(36.8)$ & 79 (43.4) & $11(6.0)$ & $182(100.0)$ \\
\hline $\begin{array}{l}\text { The state should ensure that every child receives all } \\
\text { vaccines from the vaccination calendar. }\end{array}$ & $12(6.6)$ & $18(9.9)$ & $40(22.0)$ & $84(46.2)$ & $28(15.4)$ & $182(100.0)$ \\
\hline $\begin{array}{l}\text { Generally recommended childhood vaccinations } \\
\text { provide major benefits to the children being vaccinated. }\end{array}$ & $7(3.8)$ & $10(5.4)$ & 87 (47.3) & 71 (38.6) & $9(4.9)$ & $184(100.0)$ \\
\hline $\begin{array}{l}\text { The health benefits of obtaining recommended } \\
\text { childhood vaccinations outweigh the health risks. }\end{array}$ & $6(3.5)$ & $11(6.4)$ & $99(57.9)$ & $46(26.9)$ & $9(5.3)$ & $171(100.0)$ \\
\hline $\begin{array}{l}\text { Generally recommended childhood vaccinations pose a } \\
\text { high risk to the children being vaccinated. }\end{array}$ & $6(3.3)$ & $57(31.7)$ & 89 (49.4) & $22(12.2$ & $6(3.3)$ & $180(100.0)$ \\
\hline $\begin{array}{l}\text { Children who receive the generally recommended } \\
\text { childhood vaccinations have a higher risk of developing } \\
\text { autism than children who are not vaccinated. }\end{array}$ & $10(5.4)$ & $56(30.4)$ & $101(54.9)$ & $14(7.6)$ & $3(1.6)$ & $184(100.0)$ \\
\hline $\begin{array}{l}\text { Children who receive the recommended childhood } \\
\text { vaccinations have a higher risk of developing diabetes } \\
\text { mellitus than children who are not vaccinated. }\end{array}$ & $13(7.1)$ & $66(36.1)$ & $92(50.3)$ & $9(4.9)$ & $3(1.6)$ & $183(100.0)$ \\
\hline $\begin{array}{l}\text { Children who receive the generally recommended } \\
\text { childhood vaccinations have a higher risk of cancer } \\
\text { than children who are not vaccinated. }\end{array}$ & $18(9.8)$ & 71 (38.6) & $88(47.8)$ & $5(2.7)$ & $2(1.1)$ & $184(100.0)$ \\
\hline $\begin{array}{l}\text { Vaccines are a safe and effective way to prevent serious } \\
\text { diseases. }\end{array}$ & $10(5.5)$ & $16(8.8)$ & $71(39.0)$ & $73(40.1)$ & $12(6.6)$ & $182(100.0)$ \\
\hline $\begin{array}{l}\text { Parents should have the freedom to decide to vaccinate } \\
\text { their child or not. }\end{array}$ & $15(8.1)$ & $19(10.2)$ & $38(20.4)$ & $66(35.5)$ & $48(25.8)$ & $186(100.0)$ \\
\hline $\begin{array}{l}\text { In } \mathrm{BA} \text { there is a general increase in the number of } \\
\text { parents who vaccinate their children in accordance } \\
\text { with the vaccination calendar. }\end{array}$ & $10(5.4)$ & $30(16.1)$ & $80(43.0)$ & $59(31.7)$ & $7(3.8)$ & $186(100.0)$ \\
\hline
\end{tabular}


that parents should have the freedom to decide to vaccinate their child or not. (Table 4)

In order to conduct further analysis, the average attitude score was calculated from items 1-16, in a way that higher score indicated a more positive attitude. The theoretical range was $1-5$. From the sample, 157 mothers provided answers to all 16 items. The average attitude score was 3.24 $(\mathrm{SD}=0.49)$, which indicates a mostly neutral attitude, with a tendency towards a more positive attitude. The minimal score obtained was 1.19 , and the maximum score was 4.77 .

To investigate the association between the average positivity of attitude and other socio-demographic variables, and variables related to the number of vaccines received, Spearman's rho correlation coefficient was calculated and is presented in Table 5 .

There was no significant correlation between the average positivity of attitude and the mother's age, the number of children, education level and economic status $(\rho=0.145, P>0.05)$. Furthermore, there was no significant difference in the average positivity of attitude according to the mother's working status (Mann-Whitney $\mathrm{U}$ test for two independent groups: $\mathrm{U}=2596.0 ; \mathrm{P}=0.156$ ).

\section{Table 5. Correlation between Attitude and Socio- demographic Variables}

\begin{tabular}{|c|c|c|c|c|}
\hline \multirow{2}{*}{$\begin{array}{l}\text { Socio-demographic } \\
\text { variables } \\
\text { Average positivity } \\
\text { of the attitude }\end{array}$} & 1. & 2. & 3. & 4. \\
\hline & $\begin{array}{l}\text { Mother's } \\
\text { age }\end{array}$ & $\begin{array}{l}\text { Number of } \\
\text { children }\end{array}$ & Education & \\
\hline 1. Mother's age & 0.052 & - & - & - \\
\hline $\begin{array}{l}\text { 2. Number of } \\
\text { children }\end{array}$ & 0.015 & $0.435^{\circ}$ & - & - \\
\hline 3. Education & 0.141 & $0.204^{\dagger}$ & 0.022 & - \\
\hline $\begin{array}{l}\text { 4. Economic } \\
\text { status }\end{array}$ & 0.144 & 0.074 & -0.003 & $0.153^{\dagger}$ \\
\hline
\end{tabular}

"Correlation is significant at the 0.01 level (2-tailed); ${ }^{\dagger}$ Correlation is significant at the 0.05 level (2-tailed).

\section{Discussion}

Vaccination programs have contributed to the decline in mortality and morbidity from various infectious diseases and vaccination is considered to be one of the greatest achievements of public health. Despite all its benefits, vaccination is perceived as unsafe and unnecessary by an increasing number of individuals and some organized groups. Vaccine hesitancy - according to WHO - is defined as the reluctance or refusal to vaccinate despite the availability of vaccines. In 2019, WHO declared vaccine hesitancy as one out of ten threats to global health (17). Individuals have been hesitant or unsure about vaccination since the first vaccines were made available. To be successful, vaccination programs rely on a high uptake level. It is estimated that less than $5-10 \%$ of individuals have strong anti-vaccination attitudes (18).

However, a more significant proportion could be categorized as being hesitant regarding vaccination. Despite the fact that it seems impossible to quantify precisely the proportion of the population that could be categorized as vaccine-hesitant, experts worldwide acknowledge that there is an increasing trend towards vaccine hesitancy (19). Attitudes to vaccination can be seen as a continuum ranging from total acceptance to complete refusal. Parents' attitudes about vaccination could result in vaccination hesitancy. The results of research into parents' attitudes towards vaccination conducted by numerous authors show that parents have both anti- and pro-vaccination views at the same time, and that they are not mutually exclusive $(7,8,9$, 10). Our research confirmed this. Additionally, in this research we obtained the high percentage of the answer "neither agree nor disagree" for almost all the questions, and this may either be a "hidden do not know" (i.e., the respondent has no opinion), or it can mean a neutral opinion (i.e., the respondent is somewhere between agreeing and disagreeing). This was especially the case for the statement about the risk of developing certain diseases, where the answer "neither agree nor disagree" indicates that respondent does not have an opinion and/or does not know. The highest percentage of "neither agree nor disagree" was expressed for the connection between vaccination and autism, a lower percentage for the connection with diabetes mellitus, and the lowest for cancer. In the media, and especially social media networks, there is still very often informa- 
tion about the connection between vaccination and autism, and attitudes of mothers in this survey are probably influenced by that. Research conducted by Serpell and Green (20), Evans et al. (21), Woo et al. (22) and Smailbegovic (23) also highlights the importance of vaccination risk assessment, and the relationship between the magnitude of the estimated risk and the expected benefit (the positive effects of vaccination).

In our study, more than half of the participants had a positive personal experience with vaccination. About $30 \%$ of participants claimed that many people they know had a negative experience with vaccination. We can question if those are people they know personally or people "known" through social media networks. The social media networks allow lay people to express their opinions, which then spread at a high speed, and along the way, the facts about the first author of the statement are lost. It is often the case that the story of one and the same "harmful" event is repeated several times, giving the false impression that there are many such events. Respondents of different ages, and educational and employment status did not differ significantly in their average scores on the vaccination attitudes' scale. Our results confirm this. We did not find any correlation between the positivity of attitude towards vaccination and the mothers' ages, the number of children, or educational and economic status. Research about the Dutch childhood vaccination program showed the negative attitude of highly educated parents and health care workers towards future vaccinations (24). Similarly, research from France showed that the vaccine refusal and delay are frequent among French parents, especially the more educated (25). Our respondents expressed a desire to make their own decision about the vaccination of their children in a high percentage, $61.3 \%$. This could potentially lead to a lower response rate to compulsory vaccination. In this situation, it is questionable whether parents have enough professional and credible medical information to make an informed choice. A study in eighteen European countries stressed the importance of the different types of healthcare providers. Parents who consulted general practitioners were more hesitant than parents who consulted pediatricians (26). A lack of trust in mainstream medicine and underlying conspiracy theories present in the public could also contribute to vaccination hesitancy.

In our study, attitude answers are grouped around the middle, neutral answer, which reduces variability. With a larger sample and more variability in attitude answers and educational level as well, a certain correlation could emerge.

Considering the high percentage of respondents who chose neutral, ambivalent responses, further public health education could be beneficial to develop an understanding of vaccination's population benefits, and to develop more positive attitudes towards childhood vaccination. The findings indicate the need for ongoing work with the population, through the health service, media and social media networks, to provide the public with accurate and validated data on the efficacy of and adverse reactions to vaccination. The experts have proposed ways to counter vaccine hesitancy at the population level, including transparency in policy-making decisions regarding vaccination programs, providing education and information to the public and health providers about the strictly regulated process that leads to approval of new vaccines, and diversified post-marketing surveillance of vaccine related events. In recent times there have been attempts to educate children themselves about infectious diseases and vaccination through play. In Australia they tried it through a card game called Vaxcards (27). The influence of perceived safety on vaccine hesitancy has been a finding of several meta-analyses of the scientific literature (28). As a result, additional emphasis should be placed on listening to the concerns, and understanding the perceptions of the public, to inform communication of risk, and to incorporate public perspectives in planning vaccine policies and programs. The role of health professionals is crucial in sustaining the success of vaccination programs, so more research is needed to understand why some health professionals, trained 
in medical sciences, still have doubts regarding the safety and effectiveness of vaccination.

\section{Limitations}

A selection bias might be possible because this was a convenience sample and not a random one. A social desirability bias is also possible, since survey respondents tend to answer questions in a manner that will be favorably viewed by others. Therefore, it is possible that some of the respondents privately actually have more negative attitudes than they expressed in the survey.

\section{Conclusion}

This research provides an insight into mothers' attitudes towards vaccination. The results of the research did not confirm any effect of the respondents' age, their employment status and education on vaccination attitudes. This research was conducted before the COVID-19 pandemic, and it will be interesting to follow parents' attitudes about vaccination after coping with the pandemic.

Authors' Contributions: Conception and design: AM; Acquisition of data: VT; Analysis and interpretation of data, drafting the article: GN; Editing and revising the article for important intellectual content: ILL; Revising the article critically: AM; Approved final version of the manuscript: AM and GN.

Conflict of Interest: The authors declare that they have no conflict of interest.

\section{References}

1. Greenwood B. The contribution of vaccination to global health: Past, present and future [Internet]. Phil. Trans. R. Soc. B 369: 20130433. 2014 [cited 2021 Jan 15]. Available from: http://dx.doi.org/10.1098/rstb.2013.0433.

2. Vanderslott S, Dadonaite B, Roser M. Vaccination - Our World in Data [Internet]. 2013 [cited 2021 Jan 15]. Available from: https://ourworldindata.org/vaccination

3. World Health Organization [homepage on the Internet]. Geneva: World Health Organization; c2020 [updated in 2019; cited 2020 Dec 20]. Immunization; [about 2 screens]. Available from: https://www.who.int/newsroom/facts-in-pictures/detail/immunization.
4. World Health Organization [homepage on the Internet]. Geneva: World Health Organization; c2020 [updated in 2015; cited 2020 May 11]. Immunization coverage; [about 2 screens]. Available from: https://www.who.int/ news-room/fact-sheets/detail/immunization-coverage.

5. Burns IT, Zimmerman RK. Immunisation barriers and solutions. J Fam Pract. 2005;54(1):58-62.

6. Chen, RT. Vaccine risks: real, perceived and unknown Vaccine. 1999;17(Suppl 3):S41-6.

7. Downs JS, de Bruin WB, Fischhoff B. Parents' vaccination comprehension and decisions. Vaccine. 2008;26(12):1595607.

8. Freed GL, Clark SJ, Butchart AT, Singer DC, Davis MM. Parental vaccine safety concerns in 2009. Pediatrics. 2010;125(4):654-9.

9. Larson HJ, Cooper LZ, Eskola J, Katz SL, Ratzan S. Addressing the vaccine confidence gap. Lancet. 2011;378:526-35.

10. Janković S. Anti-vakcinalni pokreti i naučna medicina. Biomedicinska istraživanja. 2014;5(1):59-65.

11. Gangarosa EJ, Galazka AM, Wolfe CR, Phillips LM, Gangarosa RE, Miller E, et al. Impact of anti-vaccine movements on pertussis control: the untold story. Lancet. 1998;352:356-61.

12. Gellin BG, Maibach EW, Marcuse EK. Do parents understand immunisations? A national telephone survey. Pediatrics. 2000;106(5):1097-102.

13. Bennett P, Smith C. Parents attitudinal and social influences on childhood vaccination. Health Educ Res. 1992;7(3):341-8.

14. Neumann DA, Garel M, Penner D, Boles A. Parental Knowledge and Attitudes about Childhood Immunization: Attitudes About Childhood Immunization - 2003 Survey Results Abstract. The 38th National Immunization Conference; Nashville, USA; 2004 May 11-14.

15. Bralić I. Cijepljenje: najuspješniji preventivni program. Paediatr Croat. 2016;60(Supl.1):152-9.

16. Kahan DM. Vaccine Risk Perceptions and Ad Hoc Risk Communication: An Empirical Assessment. SSRN Electron J [Internet]. 2014 [cited 2014 May 10]. Available from: https://papers.ssrn.com/abstract=2386034.

17. World Health Organization [homepage on the Internet]. Geneva: World Health Organization; c2020 [updated in 2019; cited 2020 Dec 12]. Ten threats to global health in 2019; [about 11 screens]. Available from: https:// www.who.int/news-room/spotlight/ten-threats-to-globalhealth-in-2019. 
18. Matta P, El Mouallem R, Akel M, Hallit S, Fadous Khalife MC. Parents' knowledge, attitude and practice towards children's vaccination in Lebanon: Role of the parent-physician communication. BMC Public Health [Internet]. 2020 [cited 2021 Jan 10];20(1). Available from: https:// doi.org/10.1186/s12889-020-09526-3.

19. Editorial. Vaccine hesitancy: a generation at risk. Lancet Child Adolesc Health. 2019; 3(5):281.

20. Serpell L, Green J. Parental decision-making in childhood vaccination. Vaccine. 2006;24(19):4041-6.

21. Evans M, Stoddart H, Condon L, Freeman E, Grizzell M, Mullen R. Parents' perspectives on the MMR immunisation: a focus group study. $\mathrm{Br} \mathrm{J}$ Gen Pract. 2001;51(472):904-10.

22. Woo EJ, Ball R, Bostrom A, Shadomy SV, Ball LK, Evans $\mathrm{G}$, et al. Vaccine risk perception among reporters of autism after vaccination: vaccine adverse event reporting system 1990-2001. Am J Public Health. 2004;94(6):990-5.

23. Smailbegovic MS, Laing GJ, Bedford H. Why do parents decide against immunisation? The effect of health beliefs and health professionals. Child Care Health Dev. 2003;29:303-11.
24. Hak E, Schonbeck Y, De Mleker H, Van Essen GA, Sanders EAM. Negative attitude of highly educated parents and health care workers towards future vaccinations in the Dutch childhood vaccination program. Vaccine. 2005;23(24):3103-7.

25. Bocquier A, Fressard L, Cortaredona S, Zaytseva A, Ward J, Gautier A, et al. Social differentiation of vaccine hesitancy among French parents and the mediating role of trust and commitment to health: A nationwide cross-sectional study. Vaccine. 2018;36(50):7666-73.

26. Hadjipanayis A, Esso D, Torso S, Dornbusch HJ, Michailidou K, Minicuci N, et al. Vaccine confidence among parents: Large scale study in eighteen European countries. Vaccine. 2020;38(6):1505-12.

27. Tang PK. Vaccination and immunisation: can they be taught to children? Lancet Child Adolesc Health. 2017;1(1):14.

28. Palm R, Bolsen T, Kingsland JT. The Effect of Frames on COVID-19 Vaccine Hesitancy. medRxiv [Internet]. 2021 Jan 1;2021.01.04.21249241. Available from: http://medrxiv.org/content/early/2021/01/06/2021.01.04.21249241. abstract. 